\title{
CEGEO - UM CURSO ESPECIAL DE FORMAÇÃO EM GEOGRAFIA, COM DIRETRIZ NA EDUCAÇÃO DO CAMPO.
}

\section{CEGEO - Un curso de formación especial en la geografía, con Orientación en Educación Rural}

\author{
Diana da Silva Alves \\ Licenciada em Geografia pela Faculdade de Formação de Professores da UERJ \\ diana.salves@yahoo.com.br
}

Artigo recebido em 09/07/2013 e aceito para publicação em 14/12/2013

DOI: 10.12957/tamoios.2013.7362

RESUMO Este artigo tem por objetivo dar visibilidade à experiência de formulação e construção do CEGeo/Curso Especial de Geografia, que através de políticas publicas como o PRONERA/Programa Nacional de Educação na Reforma Agrária teve por objetivo oferecer ensino superior, público e de qualidade aos moradores do campo ligados aos movimentos sociais e à luta pela reforma agrária. Desta forma, buscamos ressaltar as principais características que distinguem este Curso Especial de um curso regular de Geografia, além das dificuldades de sua implementação, e a importância de sua criação.

Palavras chaves: Ensino Superior, Ensino de Geografia, Campo, Formação de Professores, Educação do Campo.

RESUMEN Este artículo tiene como objetivo dar visibilidad a la experiencia de formulación y construcción del CEGeo/Curso Especial de Geografía, que través de las políticas públicas como PRONERA/Programa Nacional de Educación en la Reforma Agraria, tiene por objetivo a ofrecer educación superior, pública y de calidad a residentes del campo vinculados a los movimientos sociales y la lucha por la reforma agraria. Por lo tanto, buscamos resaltar las principales características que distinguen este Curso Especial de un curso regular de Geografía, más allá de las dificultades de su aplicación, y la importancia de su creación.

Palabras clave: Educación Superior, Enseñanza de Geografía, Formación del Profesorado, Educación del Campo. 


\section{INTRODUÇÃO}

O Curso Especial de Geografia/CEGeo realizado pela Universidade Estadual Paulista Júlio de Mesquita Filho/UNESP em parceria com o Instituto Nacional de Colonização e Reforma Agrária/INCRA, o Programa Nacional de Educação na Reforma Agrária/PRONERA ${ }^{\mathrm{i}}$, e a Escola Nacional Florestan Fernandes/ENFF ${ }^{\mathrm{ii}}$, foi uma experiência de educação a nível superior, abrangendo as titulações de bacharel e licenciatura em Geografia, que baseado nas diretrizes da educação do campo, buscou em sua estrutura e realização oferecer uma educação de qualidade aos sujeitos moradores do campo, oriundos de movimentos sociais.

Este curso foi projetado com o intuito de oferecer aos seus estudantes uma educação diferenciada daquela tradicionalmente oferecida nos cursos regulares de Geografia, possibilitando a formulação de um currículo que contemplasse de forma mais ampla a realidade agrária, ou seja, aquela vivida pelo público alvo deste curso.

\section{REVINDICAÇÃO E REALIZAÇÃo}

Os movimentos sociais como o MST/Movimento dos Trabalhadores Rurais Sem Terra, preocupados tanto com a garantia de viver da terra, quanto com a manutenção de sua vida nela, viram na educação uma forma de fortalecer a sua luta. Dessa forma, procuraram através da formação escolar, em escolas públicas e de qualidade, colocar em foco a realidade do campo brasileiro e suas principais questões. Na luta por essa forma de educar, é construído o que conhecemos hoje por Educação do Campo.

A Educação do Campo surge através da luta de vários educadores e militantes do MST, que percebem a necessidade de se valorizar o espaço e as vidas dos sujeitos que habitam o campo, dando a estes o direito a uma educação adequada tanto a sua realidade, quanto as suas necessidades. Valoriza em si, a consciência política e a formação de sujeitos autônomos, no pensar e no agir, capazes de gerenciar as próprias lutas, buscando no trabalho e na conquista pela terra, a sabedoria para lidar com questões coletivas, como os seus direitos enquanto cidadãos.

Essa luta envolve abertura de escolas, permanência nas escolas e não fechamento de escolas ${ }^{\text {iii }}$, além da reivindicação de Projetos Político Pedagógico/PPP críticos à realidade do campo brasileiro, onde a educação seja no e do Campo. (CALDART, 2012) Segundo ela:

A Educação do Campo nomeia um fenômeno da realidade brasileira atual, protagonizado pelos trabalhadores do campo e suas organizações, que visa incidir sobre a política de educação desde os interesses sociais das comunidades camponesas. Objetivo e sujeitos a remetem às questões do trabalho, cultura, do conhecimento e das lutas sociais dos camponeses e ao embate (de classe) entre projetos de campo e entre lógicas de agricultura que têm implicações no projeto do país e de sociedade e nas concepções de política, de educação e de formação humana. (CALDART, R. S.; et al (org.), 2012, pág. 259) 
Dentre as grandes críticas que a Educação do Campo traz à educação rural, estaria a contraposição de suas ideologias. Caldart (2004, 2008 e 2012) afirma que a educação rural, seria aquela designada à manutenção da apropriação e desenvolvimentos dos meios capitalistas de produção do espaço agrário. Comprometida com o agronegócio, desvincula a concepção de espaço rural como espaço de reprodução da vida dos trabalhadores, colocando-o apenas como produtor de mercadorias para a cidade, tanto de cunho nacional ou internacional.

Ou seja, a submissão do campo à cidade encontra-se prevista no quadro de desenvolvimento econômico capitalista do agronegócio brasileiro. Outra questão pertinente à proposta da educação rural seria a invisibilidade dos sujeitos e de suas representações sociais e culturais, reduzindo-os apenas a força de trabalho. Esta questão pode ser evidenciada claramente em análises de livros didáticos de Geografia das séries do ensino básico, presentes em escolas rurais e urbanas, onde a imagem do campo é retratada como atrasado, sendo local apenas de cultivo de alimentos seja vegetal ou animal. Enquanto que a cidade é representada como local de convivência e produção cultural das "pessoas" em geral.

Questões como calendário escolar desconexo com a realidade local, e/ou imposição de análises do espaço agrário por pessoas que ali não habitam, provocando um diacronismo entre quem vivencia o espaço e quem à distância fala dele. Além da valorização das relações da vida urbana frente à realidade rural, para nos remetermos apenas a alguns exemplos que envolvem esta problemática.

A luta pela Educação do Campo, configurada pela educação pública e de qualidade, respeitadora das particularidades de campo e de seus sujeitos, apresenta muitos desafios estruturais e históricos no que diz respeito ao grande número de analfabetos e pessoas com escolaridade inferior à conclusão do ensino fundamental. Na luta por sanar essa situação, movimentos sociais já realizaram outros convênios com o INCRA através do PRONERA em busca de auxiliar na alfabetização de vários moradores do campo, experiências referentes ao nível fundamental e médio também podem ser relatadas, porém a nível universitário, esta foi a primeira experiência de formação de bacharéis e licenciados em Geografia. Esta iniciativa marca positivamente uma profunda e extensa luta pelos direitos à educação para qualquer cidadão trabalhador, como afirmam documentos importantes como a constituição de nosso país. Segundo Thomaz Jr. (2007):

Em meio a esse campo de disputas tem-se muito claro que esse curso é uma oportunidade imprescindível para possibilitar que parcelas da classe trabalhadora lutem também para recuperar o valor do estudo, do conhecimento, para capacitarem-se a interpretar o momento que estão vivendo, as contradições que povoam a sociedade nessa viragem do século XXI. Então, a luta pela Reforma Agrária e as disputas e embates contra o latifúndio e o capital não devem ser entendidas como algo distante da luta pelo acesso à Universidade Pública, à formação profissional em Geografia, à habilitação de qualidade, etc. Por esse caminho entendemos ser possível a busca de alternativas e saídas para os problemas cruciais da classe trabalhadora, e a formação universitária é uma das ferramentas fundamentais. (THOMAZ Jr, 2007, pág.8)

Neste sentido, consideramos a importância da experiência de formação dos professores de Geografia licenciados pela UNESP, sob a coordenação do professor Antonio Thomaz Junior, em convênio com o PRONERA, gerando uma atuação conjunta entre universidade e movimentos sociais, na busca de formar grupos de educadores capazes de entender e produzir análises de suas experiências cotidianas dentro de sua luta por direitos. Aptos a levar às escolas do campo a compreensão do espaço 
agrário dentro da matriz geográfica, com repercussões positivas e pertinentes, tanto aos seus movimentos sociais de origem como a forma de educar que estes defendem.

\section{O PROCESSO DE CRIAÇÃO DO CURSO}

O CEGeo nasceu de uma proposta apresentada pelos movimentos sociais articulados com a Via Campesina, envolvidos na luta pela reforma agrária, entre eles estão: o MST/Movimento dos Trabalhadores Rurais Sem Terra, o MAB/Movimento dos Atingidos por Barragens, EFA/Escola Família Agrícola- e o MPA/Movimento dos Pequenos Agricultores.

Esta proposta fala da necessidade de fornecer educação superior pública e de qualidade aos militantes envolvidos e atuantes na área da educação, na perspectiva de ampliar seus conhecimentos pessoais e suas possibilidades de elaboração e atuação dentro dos seus respectivos movimentos sociais, beneficiando tanto o setor de educação destes movimentos, como o público com quem estes lidam, como alunos, colegas de trabalho e a comunidade em geral.

A busca pelo ensino superior público e de qualidade representa o avanço das reflexões sobre a educação do/para o campo que se deseja e a responsabilidade do Estado para a sua realização.

Desta forma, promover a integração de um grupo de origem popular ao ensino superior, que sem esta oportunidade não poderia ingressar no espaço acadêmico ${ }^{\text {iv }}$, se tornou um compromisso afirmado entre os movimentos sociais e a universidade.

Para tanto foi necessário realizar uma parceria entre o INCRA, através do PRONERA e a UNESP-PP. Foram realizadas diversas reuniões para a formulação de um PPP que permitisse contemplar as necessidades deste público com demandas tão distintas daquelas apresentadas nos cursos regulares.

Logo ficou definido que a educação ali oferecida iria contemplar um currículo crítico de Geografia, que ao mesmo tempo que proporcionasse uma grande carga teórica, proporcionaria experiências de ordem prática. Desta forma foi adotada a pedagogia da alternância como organizadora da grade acadêmica, onde haveria o tempo escola e o tempo comunidade. Esta forma de pedagogia prevê uma delimitação entre tempo escola e tempo comunidade, possibilitando aos alunos uma dedicação maior aos estudos no tempo escola, enquanto que no tempo comunidade, além de compartilhar com seus pares o que aprendem no tempo escola, trabalham em suas terras sem comprometer suas criações, plantações e/ou estudos. Mais que isso, é uma metodologia que propõe atrelar a teoria com a prática. Segundo Arroyo (2012), novas pedagogias, como a da Alternância, vem sendo adotadas como forma de a formação plena do ser humano, atrelando o trabalho, relações sociais, educação escolar e produção da existência.

O total de vagas seria de sessenta (60), além do curso ser dividido em etapas, estando a localização do tempo escola partilhado entre a UNESP-PP e a ENFF.

Outra proposta seria dar ênfase em desenvolvimento territorial rural, porém este teve que ser retirado da proposta final do curso, como exigência do conselho da Câmara Central de Graduação/CCG da UNESP, para que o curso fosse aprovado.

Quando o PPP foi aprovado e seguiu para o Conselho de Ensino e Pesquisa/CEPE, surgiram outras barreiras que congelaram o prosseguimento e aprovação final para implementação do projeto. Argumentos como existência de outros cursos regulares de Geografia, falta de professores doutores ${ }^{\mathrm{v}}$ concursados e a falta de relevância em associar um curso de graduação à ação vi , planejamento e atuação de movimentos sociais demonstravam o descaso como o reflexo de um preconceito de classe, que o conselho apresentava sobre a realidade educacional vivida pelos estudantes moradores no campo. Esta atitude apenas elucidava uma deliberada oposição do conselho à presença dos camponeses organizados na Universidade. 
Desta forma os organizadores do CEGeo, passaram a ter como meta, defender a entrada de alunos camponeses na Universidade através de dois momentos. $\mathrm{O}$ primeiro consistiu na recuperação do compromisso afirmado entre a Universidade e a sociedade consolidado no estatuto da UNESP, como: o acesso público, gratuito, livre de preconceitos, e articulado com a comunidade. Como pode ser visto no Artigo 2 do Capítulo I:

\section{ARTIGO $2^{\circ}$}

A UNESP rege-se pelos princípios de liberdade de pensamento e de expressão de desenvolvimento crítico e reflexivo, com o objetivo permanente de criação e de transmissão do saber e da cultura, devendo:

I - criar, preservar, organizar e transmitir o saber e a cultura por meio do ensino, da pesquisa e da extensão;

II - oferecer ensino público, gratuito e de qualidade, sem discriminação de qualquer natureza;

III - formar cidadãos capacitados para o exercício da investigação e das diferentes profissões;

IV - privilegiar e estimular a atividade intelectual e a reflexão continua da sobre a sociedade brasileira, defendendo e promovendo a cidadania, os direitos humanos e a justiça social;

V - promover atividades de extensão e de articulação com a comunidade.

(Estatuto da UNESP, apud THOMAZ Jr, 2007, pág.6)

Impedir ou negligenciar a formação do curso, significaria que o conselho do CEPE estaria contrariando ou até mesmo negando o estatuto interno da UNESP. Com a construção deste tiveram a oportunidade de participar de uma nova reunião do CEPE, onde poderiam esclarecer e defender a criação do CEGeo.

No segundo momento procuraram organizar materiais sobre as experiências de formação escolar em áreas de reforma agrária, onde existissem convênios entre movimentos sociais, as escolas do campo e a universidade, que produziram impactos positivos na formação de seus alunos. Estes seriam utilizados como argumentos em defesa do CEGeo na nova reunião com a CEPE.

Com isso, a relevância do PRONERA foi posta em questão. Documentos, livros e dissertações que relatavam a significância da atuação do PRONERA em vários níveis, desde a Alfabetização de Jovens e Adultos/EJA, até a Educação Básica e Ensino Médio e Técnico foram coletados e organizados. A sua relevância se mostrou na formação escolar de vários sujeitos do campo, de diversas idades que não poderiam frequentar o horário regular e/ou a rotina de uma escola, ou seja, nunca alcançariam o êxito de se formarem sem a existência deste programa. Uma das características do PRONERA, desde sua proposta em 1998, foi a atuação conjunta entre movimentos sociais e universidade, seja estaduais e/ou federais, onde a atuação destes buscou e ainda busca auxiliar no desenvolvimento de uma educação nos moldes necessários à realização do PRONERA, gerando um caráter legítimo ao Programa e beneficiando alunos moradores do campo.

Após a montagem de tais documentos, assim como o rebatimento às críticas infundadas, como a falta de professores ${ }^{\text {vii }}$, além da busca de novos aliados internos na UNESP, levaram à preparação para a nova reunião do CEPE. Esta era a reunião mais importante até o momento, não havendo muitas alternativas caso a proposta fosse recusada desta vez. Durante o conselho o Vice-Reitor da UNESP demonstrou claramente seu posicionamento contrário à criação do curso, no entanto a Pró-Reitora de 
Graduação da UNESP defendeu de forma enfática e direta a criação do CEGeo, além de seus coordenadores recorrerem ao argumento que define o principio social da universidade pública, que deve promover o acesso da classe trabalhadora à universidade.

A aceitação deste curso pela comunidade universitária não foi simples nem fácil, após duas tentativas frustradas, muito esforço e aplicação dos coordenadores do projeto ali defendido, o curso foi aprovado em 2006 acontecendo o acordo formal entre o INCRA e a UNESP, no âmbito do PRONERA nas seguintes circunstâncias: a forma de ingresso no curso ocorreria através do concurso de vestibular promovido pela UNESP; seria oferecido apenas para candidatos das regiões sul e sudeste do Brasil, domiciliados em áreas de reforma agrária. Desta forma o candidato deveria apresentar no ato da inscrição seu comprovante de escolaridade do ensino médio concluído e reconhecido pelo MEC, além de uma certidão fornecida pelo INCRA que garantisse a sua situação social.

Por pressões políticas e financeiras o curso aprovado em novembro de 2006 teria apenas dois meses para selecionar seus candidatos, e suas matrículas deveriam acontecer no mais tardar em janeiro de 2007.

Prejudicados pelo pouco tempo disponível para a divulgação do curso, um público alvo reduzido $^{\text {viii }}$, além das distâncias enfrentadas entre as regiões brasileiras selecionadas foram realizadas sessenta e uma (61) inscrições, nas quais houve uma desistência por não comparecimento no vestibular. Dos sessenta (60) avaliados, todos foram declarados aptos, porém um candidato desistiu por razões pessoais, restando então cinquenta e nove (59) candidatos matriculados. Esse processo seletivo foi um momento de grande tensão, pois a verba destinada à realização do curso seria depositada de acordo com o número de alunos matriculados, situação que poderia interferir na realização das atividades planejadas para a turma formada.

Após o processo seletivo em 2007 a Comissão de Elaboração do CEGeo, que foi responsável por todo trajeto alcançado até este momento, foi dissolvida dando lugar à criação da Coordenação Político Pedagógica do CEGeo. Neste grupo estavam envolvidos representantes da FCT/UNESP dos quais destacaremos o Prof. Dr. Antonio Thomaz Junior (coordenador do CEGeo) e Prof. Dr. Bernardo Mançano Fernandes, além de outros quatro doutorandos naquele período; representantes dos Movimentos Sociais, as pedagogas Marisa de Fátima Luz e Márcia Merisse; representante do INCRA, a chefe do setor de acompanhamento de convênios do PRONERA e por fim, a representação estudantil.

Ainda houve a formação de uma equipe de monitoras, sendo elas mestres e doutoras integrantes do MST e do MAB, destinadas ao acompanhamento dos estudantes durante o tempo comunidade, além de uma secretária (FCT/UNESP) para o acompanhamento do curso.

Ficou então definido que a Coordenação Política Pedagógica estaria responsável pelas escolhas teórico-metodológicas pertinentes a cada etapa, promoveria a interlocução e discussão metodológica entre os educadores do curso, planejaria e faria com que se cumprissem todas as etapas do curso, entre outras questões de cunho pedagógico, financeiro, técnico e operacional.

\section{CONCEPÇÃO PEDAGÓGICA}

Para cada etapa seja tempo escola ou comunidade, foram pensadas metas de aprendizagem que mesclassem as dimensões política, científica e técnica. A busca por formas interdisciplinares de organizar os conteúdos levou à elaboração de alguns objetivos a serem alcançados pelos alunos ao fim do curso, como: 
- "Conhecer as linhas gerais sobre algumas áreas das ciências humanas (geografia, história, economia, sociologia, filosofia e educação)."

- "Refletir criticamente sobre os pressupostos teórico-metodológicos da ciência geográfica."

- "Conhecer os principais métodos, procedimentos e instrumentos de pesquisa geográfica."

(THOMAZ JR, 2007, pág. 20)

No tempo escola as atividades foram divididas entre os períodos de janeiro/fevereiro sediado na FCT/UNESP em Presidente Prudente, e o de julho, sediado na ENFF em Guararema-SP.

O tempo escola foi marcado por muitas horas de estudo diárias, o cronograma previa disciplinas concentradas em uma ou duas semanas, variando de acordo com a carga horária estabelecida. Houve um grande esforço tanto por parte dos alunos, que tinham seu dia totalmente preenchido por atividades acadêmicas, quanto por parte dos professores, em sua maioria doutores ou doutorandos em buscar novas formas metodológicas de apresentar as disciplinas, propondo adequá-las teórica e estruturalmente ao curso.

No tempo comunidade era proposto que os alunos aplicassem o que foi aprendido, fazendo uma relação entre as disciplinas e as situações presentes no seu dia a dia de assentamento, o que iria envolver uma nova forma de enxergar as relações dentro da sua área de atuação no movimento social.

Encontros eram marcados de acordo com a proximidade entre seu local de moradia e a das monitoras de tempo comunidade como colocado anteriormente. Seja de forma presencial ou pela internet as monitoras teriam o papel de auxiliar na produção do trabalho proposto para este período, avaliando a evolução de cada aluno.

Desta forma aconteceram alternadamente entre a UNESP e a ENFF oito tempos escola e mais oito tempos comunidade, auxiliados por monitoras formadas em pedagogia, tanto do MST, quanto do MAB.

\section{Considerações finais}

É no contexto de superação das enumeras dificuldades encontradas no período de criação e implementação do CEGeo, que buscamos valorizar a experiência de sua construção. Como também por refletir um período de amadurecimento e de conquista tanto da universidade como dos movimentos sociais. Por possibilitar uma formação acadêmica que respeite e contribua para a vida cotidiana dos trabalhadores do campo. Possibilitando que estes, aliados aos movimentos sociais e à luta pela terra, pudessem amadurecer suas reflexões e práticas referentes à luta pela reforma agrária, assim como a atuação docente e científica de cada um deles.

Além de representar o início de um processo de transformação e adequação dos currículos de Geografia direcionados às escolas do campo, possibilitando assim um reconhecimento das diferentes concepções de campo. No âmbito do PRONERA, esta experiência coloca a importância de se promover uma educação adequada à realidade do campo, levando a mais pessoas o direito á educação superior pública e de qualidade. 


\begin{abstract}
${ }^{\text {i }}$ Programa Nacional de Educação na Reforma Agrária, instituído pelo governo federal em 16 de abril de 1998, tem por objetivo diminuir os níveis de analfabetismo e baixa escolaridade no campo. Inicialmente atuava nos níveis básicos da educação com turmas de alfabetização e EJA, atualmente seus cursos incluem ensino médio, cursos técnicos e de ensino superior como é o caso estudado por este projeto de pesquisa. Abordaremos novamente este tema mais adiante.
\end{abstract}

${ }^{i i}$ A Escola Nacional Florestan Fernandes foi fundada no ano de 2010 pelo MST, com o objetivo de oferecer cursos de formação política, que abrangessem causas coletivas como é o caso da luta pela terra. Segundo LIMA, 2012, o seu público alvo se caracteriza por minorias políticas como os militantes do MST, Indígenas, militantes da luta pela terra na América Latina e/ou África, entre outros.

Localizada em Guararema, São Paulo, teve sua estrutura construída através de trabalho voluntário e doações, hoje composta por salas de aula, refeitório, dormitórios, hortas, uma biblioteca que disponibiliza mais de quarenta mil títulos para seus alunos, além aproximadamente quinhentos professores voluntários, oriundos de diversas universidades conceituadas.

${ }^{i i i}$ Referência à campanha Fechar Escola é Crime, protagonizada pelo MST em 2010.

iv Não nos referimos aqui a capacidade intelectual dos alunos militantes, mas as dificuldades encontradas na tentativa de se conciliar a rotina da vida no campo e a estrutura rígida que rege a carga horária acadêmica dos cursos regulares, que se renova semestralmente.

O número final de professores Doutores ministrando o curso foi de 33 (trinta e três), com a complementação de 6 (seis) mestres e 4 (quatro) Livres Docentes.

${ }^{v i}$ Nos referimos à luta travada pelos movimentos sociais por uma educação adequada a sua realidade, que faça sentido ao cotidiano do educando, respeitando seus valores e cultura. Para tanto esta deve ser participativa, crítica e consciente tanto dos processos que a estruturam, quanto daqueles que se propõem a desmobilizá-la. Esta luta tem tomado forma na concepção da Educação do Campo, que pode ser melhor entendida a partir de CALDART, 2004.

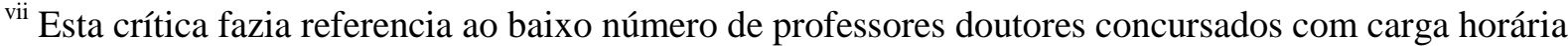
disponível para trabalhar no CEGeo. Porém esta deficiência não é uma característica exclusiva deste curso, ou do departamento de geografia da UNESP. Tal situação como alega THOMAZ (2007) vem sendo resolvida, por esta faculdade, através da contratação de Professores Doutores, a fim de suprir a carga horária necessária a realização dos cursos oferecidos.

Neste artigo não problematizaremos tal questão, apenas apresentamos esta realidade como um fato que ao longo dos anos vem aparecendo com mais frequência no setor publico de educação, onde a quantidade de contratos pode ser superior ao número de professores concursados, mas que nesta situação não poderia ser considerado como um motivo para a não criação do curso.

viii Consideramos aqui as condições históricas de descaso educacional com os moradores do campo, e como reflexo disso o baixo grau de escolaridade de muitos deles, limitando-se em muitos casos à Educação Básica. Sobre este assunto ver, ALENTEJANO, 2011. 


\section{Referencia bibliográfica}

ALENTEJANO, P. R. R. . Os desafios da educação de jovens e adultos em assentamentos e acampamentos rurais no estado do Rio de Janeiro. In: Marcia Soares de Alvarenga. (Org.). Educação de jovens e adultos: em tempos e contextos de aprendizagens. 1ed.Rio de Janeiro: Rovelle, 2011, v. 1, p. $45-62$.

ARROYO, M. G. Tempos humanos de Formação. In: CALDART. R. S et. al. (org.). Dicionário da Educação do Campo. Rio de Janeiro, São Paulo: Escola Politécnica Joaquim Vênancio, Expressão Popular. 2012.

CALDART, Roseli. Saleti. Pedagogia do Movimento Sem Terra (3 ${ }^{\mathrm{a}}$ ed.). São Paulo: Expressão Popular. 2004.

; Sobre educação do Campo. In: SANTOS, C Por uma Educação do campo (4ª ed., pp. 67-85). Petrópolis,RJ: Editora Vozes. 2008.

; Educação do Campo. In: CALDART. R. S. et. al. (org.). Dicionário da Educação do Campo. Rio de Janeiro, São Paulo: Escola Politécnica Joaquim Vênancio, Expressão Popular. 2012.

LIMA, Luci Yahell, Escola Nacional Florestan Fernandes visa a socialização do conhecimento. Movimento dos Trabalhadores Sociais Sem Terra. 2012. Disponível em: http://www.mst.org.br/Escola-Nacional-Florestan-Fernandes-visa-a-socializacao-doconhecimento\%20. Acesso em: 16 jan. 2014.

THOMAZ JR, Antonio. Relatório da $1^{\text {a }}$ Etapa do Curso Especial de Graduação em Geografia: (1 ${ }^{\circ}$ Tempo Escola $-1^{\circ}$ Tempo Comunidade), Presidente Prudente, novembro de 2007. 